\title{
Eoin Price. 'Public' and 'Private' Playhouses in Renaissance England: The Politics of Publication. London: Palgrave Macmillan, 2015. Pp x, 95.
}

HOLGER SCHOTT SYME

University of Toronto

Eoin Price has written an engaging short book that all future discussions of indoor performance in early modern England will have to take into account. In three chapters and an epilogue, he charts the development of the language used to describe indoor commercial performance spaces and analyses the complex distinctions between 'public' and 'private' playing. Although the volume will be of interest and relevance to historians of theatre, literature, and the book alike, Price's arguments largely rely on evidence gleaned from printed books and their title-pages. And yet, his study is not exactly an exercise in bibliography, nor is it precisely a work of theatre history (he barely reflects on how indoor and outdoor spaces functioned as performance venues, for instance). Instead, what Price offers is an analysis of the place of indoor staging in the period's theatrical discourse as shaped by stationers and playwrights, and occasionally by government officials, acting companies, or spectators. He is less interested in what early modern players and audiences did in and with indoor spaces than in 'the complex uses that 'public' and 'private' served to Renaissance playgoers and playmakers' (3).

Price shows that the idea of a 'private' commercial performance apparently did not emerge, in those terms, until the early seventeenth century. Even after the publication of a small cluster of plays as staged 'privately' by boys' companies in 1601 and 1602, however, it would take another decade for the term to reappear on title-pages — and, as Price argues, it was not until 1629 that 'private' displaces 'public' as the dominant term in printed playbooks. Between 1629 and 1660, though, a far greater number of plays (64 vs. 8) were advertised as staged privately rather than publicly. In a final twist, once indoor playing became the norm in the Restoration, 'private' disappeared again: all theatrical performances were 'public' at that point, even though they took place exclusively in spaces that, a few decades earlier, would have been described as 'private' (71).

Stationers and authorities, and presumably actors and playgoers as well, were evidently capable of distinguishing between different notions of privacy. Price correctly notes that when referring to performances, 'private' initially meant 'noncommercial'. Private shows were those staged in someone's house, for an invited audience, and 'there was no money collected from the auditors' (13). He argues that this sixteenth-century understanding of private performance remained in 
place until the turn of the century, when the term became more flexible; the 1601 title-page of Cynthia's Revels inaugurates the idea that a play can be 'privately acted' for a paying audience. But from the evidence Price has amassed, it seems that 'private' could also simply mean 'indoors' — and although he does not quite say so, it appears that this sense emerged somewhat earlier than the 1600s. A 1569 precept issued by the City of London urged 'Innkeepers, table-keepers, taverners, hall-keepers, or brewers' to refrain from hosting plays 'either openly or privately' (13). The aldermen obviously did not mean that innkeepers should stage neither commercial performances nor shows for their friends. Rather, the precept seems to have restricted outdoor ('open') and indoor ('private') performances, which is also why it lists outdoor spaces ('yard, court, garden, orchard') as well as the innkeepers' 'mansion house' as off limits for plays.

Price's discussion of university performances captures this slippery quality of the term 'private' (although many of his sources are in Latin, a significant complication); as it turns out, a college hall could be both a private and a public venue, whereas a college's master's lodgings seem to have been a place only for private performances (15). Halls were, of course, indoor spaces: in that sense, they were as private as the venues in which London's children's companies acted. And like those spaces, which could be considered 'common' or 'public' in the period (18), college halls could be opened up to a broader public (if not the elements): they, too, could host 'public' shows. Spaces, then, were described as 'private' in a somewhat more neutral sense than Price allows, and earlier, even though the more loaded sense in which he is primarily interested, "with its cognates "exclusive" and "select" (25), is a Jacobean phenomenon (especially as a descriptor of performances rather than spaces).

In this context, the well-known 1596 petition against James Burbage's plans to open a 'common playhouse' in the Blackfriars proves illuminating, even if Price is right in his skeptical response to the suggestion that the document 'allude[s] to an indoor theatre as "private" (18). The petitioners evidently were concerned about a change in the modalities of access to the precinct: what had been, years earlier, a small venue likely not used daily, was threatening to transform into a space open to larger audiences on most days of the week. In other words, the petitioners were not concerned about the idea of staging plays indoors, but about staging plays daily, with a relatively large audience: about one type of 'privacy', not the other.

When Price's discussion moves into the seventeenth century, it becomes apparent that 'private' and 'public' remained descriptors of spaces as well as of modalities of access, and that the former continued to dominate for a time. Satiromastix, for example, was printed 'as it hath been presented publicly, by the Right 
Honourable, the Lord Chamberlain his Servants; and privately, by the Children of Paul's' (30). What that title-page records, I would argue, is a difference not in prestige, but more straightforwardly in venue: one outdoors, the other closed to the world. As Price notes, however, it would be a mistake to think that indoor privacy implied a less public performance. Responding to the theory that 'private' stagings were not subject to the control of the master of the revels, he shows that in fact plays such as Chapman's lost Old Joiner of Aldgate and Jonson's Poetaster were licensed even though they were acted indoors. The notion that companies used the 'privately acted' tag to avoid having to submit plays to the master of the revels is clearly fanciful, and Price effectively dismantles it. 'Private' performances may have been less 'common' than outdoor shows, but they were also inevitably 'public'.

That the notion of a 'private stage' was firmly establishing itself in the early seventeenth century is supported by a wide range of evidence (36-7). But Price's data suggests that it took rather longer for the idea that indoor acting was culturally superior to take hold. His account rather implies that something else must have happened around 1612 that invested indoor playing with a new kind of value. Although the King's Men's acquisition of the Blackfriars as a permanent indoor venue may tempt scholars to think that this acquisition immediately precipitated a change in attitudes towards indoor and outdoor playing, in fact, as Alan B. Farmer and Zachary Lesser demonstrated over a decade ago, the Blackfriars is mentioned less frequently than the Globe on King's Men title-pages until 1629; the balance only shifts, but then decisively, in the 1630 s. $^{1}$

Price argues for a similarly impressive increase in mentions of 'private' performances on title-pages between 1629 and 1660, but he does not construct a grand narrative to explain this shift. Unlike Farmer and Lesser, who consistently portray stationers and their marketing interests as the agents behind these changes in vocabulary, Price tends to foreground case studies of specific plays, and devotes much space to arguments about title-page authorship. Some of these are more illuminating than others, but his insistence that the question of agency needs to be addressed on a case-by-case basis deserves praise. An extended discussion of three Heywood plays, for example, all printed in the 1630s with title-pages that advertise their indoor performances as 'public', makes the case that the unusual decision to eschew the 'private' label forms part of Heywood's campaign to defend the value of public and popular theatre — both against radical anti-theatricalists such as William Prynne and against the elitist attitudes of rival playwrights, especially William Davenant (58-64). 
In general, while Price convincingly shows that the cultural significance of 'private' and 'public' playing shifted over the decades he studies, and that claims on those labels came with increased cultural stakes later in the seventeenth century, his book does not really strike me as a study of the 'politics of publication' in the period. Price's conclusion that the two terms 'formed an important part of the politicised culture of Renaissance playmaking, playgoing, play printing, and play reading' seems to me to claim more than his book supports (73). He clearly establishes that the shifting rhetoric of privacy influenced how plays were made and received in the period. How that rhetoric connects to larger ideological, let alone political, developments is less clear; if Price wanted to develop that aspect of his argument, he would need more room and a larger archive than he has at his disposal here. Luckily, as a contribution to the study of early modern drama and its theatrical history, the book's success does not depend on addressing these broader political questions; and as such a contribution, it has much to offer.

\section{Notes}

1 Alan B. Farmer and Zachary Lesser, 'Vile Arts: The Marketing of English Printed Drama, 1512-1660', Research Opportunities in Renaissance Drama 39 (2000), 77 166, esp. $90-1$. 